\title{
Distribusi Crude Oil Melalui Alternatif Sistem Pipa Bawah Tanah Menggunakan Tekno Ekonomi
}

\author{
M Kumroni Makmuri \\ Fakultas Teknik, Program Studi Teknik Industri \\ Universitas Bina Darma \\ Jl. Jend A. Yani No 3,9/10 \\ kumroni@binadarma.ac.id
}

\author{
Andre Prabowo \\ Fakultas Teknik, Program Studi Teknik Industri \\ Universitas Bina Darma \\ J1. Jend A. Yani No 3,9/10 \\ andre prabowo@gmail.com
}

\begin{abstract}
Abstrak - Salah satu masalah yang dihadapai Pertamina RU-III Plaju Palembang saat ini, adanya in-efisiensi dalam proses pengadaan BBM mentah crude oil yang didatangkan dari beberapa sumur minyak di Indonesia yang mana masih harus melalui beberapa proses kegiatan pengapalan, dimulai dari kapal pembawa crude oil bermuatan $450 \mathrm{mb}$ yang berasal dari sumur/loading port untuk kemudian melakukan loading/unloading di kapal penampung sementara bernama MT. Adapun tujuan yang ingin dicapai dari penelitian yaitu menentukan arus kas bersih dengan dari nilai cash in dan cash out pada sistem lama distribusi crude oil, guna sebagai acuan perhitungan NPV, IRR dan menetapkan payback period, melakukan perhitungan NPV dan IRR terhadap rencana investasi sistem baru, dengan acuan arus kas bersih sistem lama distribusi crude oil serta menganalisis nilai investasi sistem baru layak atau tidak diterapkan, guna mengurangi losses, dengan penentuan kelayakan investasi dari hasil analisis arus kas bersih sistem lama dengan metode NPV dan IRR. Dari penelitian yang telah dilakukan didapatkan kesimpulan bahwa arus kas bersih yang tercipta setiap tahunnya memiliki nilai yang positif dengan nominal awal rencana investasi sistem baru yaitu sebesar Rp3,500,000,000,000. Dari perhitungan didapatkan nilai IRR $=22.38 \%>$ MARR $=15 \%$, yang artinya nilai alternative investasi sistem baru (instalasi pipa dan tanki timbun) distribusi crude oil layak (menguntungkan) untuk dijalankan. Didukung dengan payback period yang baik, yaitu selama 5 tahun serta alternatif investasi sitem baru (instalasi pipa dan tanki timbun)meminimalkan nilai losses distribusi crude oil, dimana nilai losses alternative sistem baru $=42,500 \mathrm{bl}<$ dari nilai losses sistem lama $=$ $428,386 \mathrm{bl}$.
\end{abstract}

Kata kunci - PT.Pertamina RU III Plaju, NPV, IRR, investasi, crude oil, tekno ekonomi

\section{PENDAHULUAN}

\subsection{Latar Belakang}

Kompetisi usaha saat ini menjadi suatu hal yang sangat penting, ada dua opsi utama pilihan yang perlu diperhatikan yakni efisiensi disetiap lini produksi agar dapat menekan biaya produksi, atau membiarkan tanpa penekanan pada biaya produksi tetapi orientasi pada kualitas produksi minimal terjaga pada level kualitas saat ini, hal ini menjadi penting untuk bisa bersaing atau merebut pasar yang lebih besar. pilihan pertama artinya kualitas dijaga agar tetap bertahan pada level kualitas saat ini namun dengan penekanan pada biaya produksi agar harga jual yang lebih murah, atau pilihan kedua harga tetap, tetapi kualitas produk ditingkatkan untuk meraih pasar yang lebih besar. apapun pilihannya tetap menjadi suatu pekerjaan rumah bagi manajemen perusahaan.

Demikian halnya PT. Pertamnina (Persero), yang merupakan perusahaan Badan Usaha Milik Negara (BUMN) yang bertanggung jawab dalam pengelolaan untuk pemenuhan energi (BBM) untuk industri dan sarana transportasi di Indonesia, seperti contoh kasus berikut dalam hal ini PT. Pertamina RU-III Plaju Palembang sebagai salah satu kilang minyak dari 7 kilang minyak yang dimiliki Pertamina, terus berpikir dan berusaha memperbaiki sistem yang ada, mulai dari pengadaan bahan baku, proses produksi, transportasi antar unit produksi, maupun bahan in-proses dalam rangka efisiensi dan peningkatan produksi untuk memenuhi permintaan yang juga terus menerus meningkat.

Salah satu masalah yang dihadapai Pertamina RU-III Plaju Palembang saat ini, adanya in-efisiensi dalam proses pengadaan BBM mentah crude oil yang didatangkan dari beberapa sumur minyak di Indonesia yang mana masih harus melalui beberapa proses kegiatan pengapalan, dimulai dari kapal pembawa crude oil bermuatan $450 \mathrm{mb}$ yang berasal dari sumur/loading port untuk kemudian melakukan loading/unloading di kapal penampung sementara bernama MT. Gamkonora dengan kapasitas yang 
sama berlokasi di Selat Bangka, setelah proses transfer loading selesai selanjutnya minyak yang ada di kapal MT. Gamkonora di loading lagi ke kapal shutle dengan muatan lebih kecil berkapasitas $70 \mathrm{mb}$ agar selanjutnya di bawa ke Kilang RU-III di Plaju. namun masalahnya hampir disetiap proses loading/unloading tersebut biasnya terjadi oil loss kebocoran/kehilangan yang melebihi dari nilai toleransi sejumlah $1-2,5 \%$ per kegiatan loading/unloading. dilain sisi muatan sebanyak 450 $m b$ ini memerlukan waktu seminggu jika cuaca cukup bagus untuk menyuplai penuh distribusi feed kilang RU-III di Plaju. selain kebocoran disebutkan di atas in-efisiensi lainya adalah biaya pembayaran operasional keigatan kapal-kapal di Selat Bangka bisa mencapai Rp. 1 milyar/hari.

Kedangkalan air sungai musi yang menyebabkan sistem transportasi dan bongkar muat crude oil ini bertahan dan sudah berlangsung sejak tahun 2008, artinya sudah berlangsung selama 10 tahun, dan jika dijumlahkan total seluru kehilangan crude oil ini dalam kurung waktu tersebut akan menunjukkan nilai angka yang cukup besar dalam kurs rupiah saat ini dan seandainya jika dana sebesar ini dialokasikan untuk menekan oil losses dengan memberikan alternatif sistem seperti membangun sistem baru distribusi crude oil instalasi pipa bawah tanah di Tanjung Siapi-api menuju kilang minyak RU-III Plaju Palembang untuk menggantikan sistem lama ship to ship. Tetapi muncul pertanyaan baru apakah alternative sistem baru ini yang merupakan sebuah rencana investasi yang besar layak (menguntungkan) untuk dilaksanakan untuk kedepanya dan dapat mencapai salah satu tujuan perusahaan yaitu mengurangi losses dari setiap pendistribusian crude oil.

\subsection{Tinjauan Pustaka}

Menurut Suratman [6], investasi dalam suatu perusahaan tidak lain adalah mengenai penggunaan sumber-sumber yang diharapkan akan memberikan pengembalian yang menguntungkan pada masa mendatang. Hal tersebut berarti menanamkan sejumlah modal untuk menjalankan suatu usaha atau proyek pada masa sekarang, dengan harapan adanya pengembalian modal yang juga disertai dengan keuntungan di masa yang akandatang.

Investasi merupakan penanaman modal yang diharapkan dapat menghasilkan tambahan dana pada masa yang akan datang [2]. Bisa dibilang investasi merupakan satu bentuk pengorbanan harta pada masa sekarang untuk mendapatkan keuntungan di masa depan. Jenis-jenis investasi dibedakan menjadi dua oleh [1]:

1. Investasi dalam bentuk aset riil (real assets) $=$ Yaitu investasi dalam bentuk aktiva berwujud fisik, seperti emas, batu mulia dan sebagainya.
2. Investasi dalam bentuk surat berharga/sekuritas (marketable securities financial assets) = Yaitu investasi dalam bentuk surat-surat berharga yang pada dasarnya merupakan klaim atas aktiva riil yang diawasi oleh suatu lembaga/perorangan tertentu. Investasi tentunya memiliki resiko. (Donald E. Fischer \& Ronald J. Jordan, 1995) menyatakan bahwa resiko berarti ketidak pastian dalam kemungkinan distribusi return. Dalam hal ini resiko investasi bisa dalam bentuk tidak kembalinya atau hilangnya dana yang diinvestasikan atau dengan kata lain investor mengalami kerugian. Untuk meminimalisir resiko dalam berinvestasi, perlu dilakukan pertimbangan matang dalam menentukan investasi yang akan dilakukan. Salah satu ilmu yang mempelajarinya adalah ekonomi teknik. Ekonomi teknik merupakan suatu ilmu Jurusan Teknik Industri, pengetahuan yang berorientasi pada pengungkapan dan perhitungan nilai-nilai ekonomis yang terkandung dalam suatu rencana kegiatan teknik (engineering). Nilai uang yang kita miliki sekarang berbeda dengan yang kita miliki pada masa lalu maupun yang akan datang. Untuk itu, banyak orang melakukan investasi dengan tujuan mendapatkan keuntungan lewat mengubah uang menjadi barang yang memiliki nilai yang terus berkembang.

Menurut Raharjaputra [3] investasi merupakan suatu keputusan yang diambil perusahaan berhubungan dengan perencanaan dan pendanaan suatu proyek, usaha baru atau pengembangan usaha dalam rangka pembelian peralatan baru, pengenalan produk baru dan membangun fasilitas modern

Keputusan atas investasi yang akan dilakukan oleh suatu perusahaan, terutama harus dipertimbangkan tentang berapa besar tingkat pengembalian yang diharapkan (expected return) oleh perusahaan di kemudian hari. Keputusan harus mempertimbangkan beberapa hal, yaitu :

1. Apakah dengan pembelian peralatan baru akan menekan biaya operasional perusahaan (cost reduction)

2. Apakah dengan pabrik atau fasilitas baru akan menambah kapasitas dan penjualan sehingga meningkatkan kinerja perusahaan atau nilai tambah (value added)

3. Apakah perusahaan harus sewa atau beli

4. Apakah keputusan untuk mengganti peralatan atau mesin perlu dilakukan segera

5. Apakah dana yang akan digunakan sudah memiliki biaya modal yang minimal 
Dengan pertimbangan diatas maka menciptakan persamaan sebagai berikut :

Net present value $=$ present value-initial investment $(\mathrm{X})$

Jika PV $>$ X, maka proyek memiliki NPV positif

Jika PV $<$ X, maka proyek memiliki NPV negatif

NPV digunakan untuk mengukur kinerja atau kelayakan suatu investasi.Apabila NPV proyek adalah positif, hal itu berarti terjadi peningkatan kekayaan.Bagi perusahaan, hal ini berarti bersarnya nilai positif NPV mengukur terjadinya peningkatan nilai perusahaan yang dihasilkan dari suatu investasi.Dalam menggunakan metode NPV, tingkat pengembalian di isyaratkan (required rate of return) harus didefinisikan.Tingkat pengembalian yang diisyaratkan merupakan tingkat pengembalian minimum yang dapat diterima. Tingkat pengembalian minimum yang diterima juga disebut sebagai tingkat diskonto (discount rate), hurdle rate dan biaya modal (cost of capital). Apabila NPV positif, hal tersebut menandakan bahwa :

1. Investasi awal telah tertutup

2. Tingkat pengembalian yang diisyaratkan telah berhasil dipenuhi

3. Dan tingkat pengembalian yang melebihi butir(1) dan butir (2) telah diterima

Jadi, apabila NPV lebih besar dari pada 0 , maka dapat disimpulkann bahwa investasi menguntungkan dan investasi dapat diterima. Apabila NPV sama dengan nol, maka pengambil keputusan dapat menerima atau menolak investasi tersebut. Akhirnya, apabila NPV lebih kecil dari pada nol, maka investasi sebaiknya ditolak.

Menurut Siregar [5] Metode IRR yaitu tingkat pengembalian didefinisikan sebagai tingkat bunga yang menentukan nilai sekarang dari dari arus kas masuk proyek sama dengan nilai sekarang dari biaya proyek tersebut. Dengan kata lain, IRR adalah tingkat bunga yang menjadikan NPV proyek sama dengan nol . Menurut (Kuswadi, 2007). Internal Rate of Return (IRR) adalah suatu tingkat bunga (bukan bunga bank) yang menggambarkan tingkat keuntungan dari suatu proyek atau investasi dalam persentase pada saat dimana nilai NPV sama dengan nol Rumus yang digunakan untuk menghitung IRR yaitu:

$$
\operatorname{IRR}=i_{\oplus}+\left[\frac{\mathbb{N P W}_{\square}}{\mathrm{NPV}_{\square}-\mathrm{NPW}_{\mathbb{1}}}\right]
$$

Cara menghitung nilai IRR menurut Sinaga [7] adalah sebagai berikut :

1. Menghitung arus net cash flow sepanjang umur proyek, ditambah nilai sisa dariaset.

2. Menentukan tingkat bunga pembanding yang lebih besar daritingkat rate of return, selisih sebaiknya tidak lebih besar dari 5\%.
3. Menghitung nilai IRR menggunakan rumus ada persamaan 4 .

Payback period merupakan teknik penilaian untuk mengetahui seberapa lama jangka waktu (periode) yang dibutuhkan untuk pengembalian investasi dari suatu proyek atau usaha. Rumus yang digunakan untuk menghitung Payback period adalah:

$$
\mathrm{PP}=\frac{\text { Inwestasi }}{\text { Arus kas bersih pertahun }}
$$

Untuk menilai kelayakan suatu usaha atau proyek dari segi Payback period adalah :

Jika : PP > umur ekonomis proyek, maka tidak layak.

: PP $<$ umur ekonomis proyek, maka layak.

Kelemahan dari metode Payback period adalah tidak memperhitungkan arus net profit pada tahuntahun berikutnya, begitu juga dengan nilai sisa (salvage value) yang tidak dihitung setelah investasi kembali [8]. Sedangkan kelemahan Payback period menurut Suratman [6] yaitu mengabaikan konsep nilai waktu dari uang (time value of money) dan aliran kas setelah periode pengembalian, padahal aliran kas tersebut menunjukkan tingkat keuntungan yang harus diketahui oleh investor.

\section{METODE}

\subsection{Lokasi Penelitian}

Penelitian ini dilakukan pada Divisi perkapalan PT Pertamina RU III (crew kapal dan crew darat) pendistribusian crude oil. PT Pertamina (Persero) $R U$ III yang terletak di Jln. Beringin I PO BOX 1 Plaju Palembang, Sumatera Selatan.

\subsection{Metode Pengolahan Data}

Setelah data diperoleh, proses selanjutnya yang dilakukan adalah mengolah data tersebut, dengan tetap mengacu pada tujuan penelitian. Metode pengolahan data yang digunakan dalam penelitian ini yaitu metode kuantitatif [9], menggunakan NPV dan IRR, dengan langkah proses sebagai berikut :

1. Menentukan dan menghitung cash in dan cash out dari sistem lama (ship to ship) distribusi crude oil, dari selat Bangka Muntok ke Pertamina RU III Plaju Palembang.

2. Menghitung arus kas bersih dengan mengurangkan cash in dan cash out dari sistem lama (ship to ship) distribusi crude oil yang dipengaruhi dengan tingkat inflasi.

3. Menentukan biaya rencana investasi sistem baru (instalasi pipa dan tanki timbun) distribusi crude oil. 
4. Menganalisis rencana investasi sistem baru (instalasi pipa dan tanki timbun), apakah nilai investasi sistem baru distribusi crude oil layak (menguntungkan) atau tidak untuk di laksanakan.dimana ketentuan kelayakan ditetapkan dari hasil perhitungan dan analisi arus kas bersih sistem lama(ship to ship) menggunakan metode NPV dan IRR.

\section{HASIL DAN DISKUSI}

Pengolahan data dilakukan terhadap nilai investasi sistem baru (instalasi pipa dan tanki timbun) pedistribusian crude oil, melalui acuan dasar perhitungsn cash in dan cash out sistem lama (ship to ship) pendistribusian crude oil yang akan menciptakan arus kas bersih sebagai acuan analisis NPV dan IRR. Pengolahan data dilakukan untuk mengetahui apakah nilai investai sistem baru yaitu instalasi pipa dan tanki timbun layak dilakukan untuk menggantikan sistem distribusi lama. ketentuan layak atau tidaknya investasi sistem baru pendistribusian crude oil untuk dilaksanakan, ditentukan dari hasil analisis metode Net Present Value (NPV) dan Internal Rate of Return (IRR), dengan faktor diskonto yang akan digunakan $12 \%$ dan 23\%, dengan ketentuan perusahaan Minimum Attractive Rate of Return (MARR) $=>15 \%$. Dan data nilai cash in dan cash out di pengaruhi oleh nilai inflasi $=0.02 /$ tahun dengan beban pajak perusahaan $=30 \%$ pertahun .

Perhitungan NPV dan IRR dimulai dengan menetapkan nilai investasi sebagai asumsi dasar perhitungan, menghitung cash in atau pendapatan kemudian menghitung nilai cash out ataupengeluaran. Sehingga nantinya dari pengurangan nilai cash in dan cash out yang masuk dalam laporan laba rugi,akan didapatkan arus kas bersih sebagai acuan perhitungan NPV dan IRR.

Tetapi sebelumnya adapun nilai depresiasi dari nilai investasi sistem baru (instalasi pipa dan tanki timbun) dengan estimasi nilai umur aset, $=10$ tahun dan estimasi nilai residu $=400$ miliar, yaitu sebagai berikut :

$$
\begin{aligned}
& \text { Depresiasi }=\frac{\text { Harga Perolehan-Ni }}{\text { Tekgiran Dmur Ma }} \\
& \text { Depresiasi }=\frac{\text { a,s6000 }}{10}=310,000,000,000 \\
& \text { Tarif Depresiasi }= \\
& \text { Tarif } \mathbb{D}=10 \%
\end{aligned}
$$

Tabel 1. Nilai depresiasi investasi sistem baru

\begin{tabular}{|cccccc|}
\hline Thn & $\begin{array}{c}\text { Jumlah } \\
\text { Terdepresiasi }\end{array}$ & $\begin{array}{c}\text { Tari } \\
\mathrm{f}\end{array}$ & $\begin{array}{c}\text { Biaya } \\
\text { Depresiasi }\end{array}$ & $\begin{array}{c}\text { Akumulasi } \\
\text { Depresiasi }\end{array}$ & Nilai Buku \\
1 & $3,500,000,000,000$ & $10 \%$ & $310,000,000,000$ & $310,000,000,000$ & $3,190,000,000,000$ \\
2 & $3,500,000,000,000$ & $10 \%$ & $310,000,000,000$ & $620,000,000,000$ & $2,880,000,000,000$ \\
3 & $3,500,000,000,000$ & $10 \%$ & $310,000,000,000$ & $930,000,000,000$ & $2,570,000,000,000$ \\
4 & $3,500,000,000,000$ & $10 \%$ & $310,000,000,000$ & $1,240,000,000,000$ & $2,260,000,000,000$ \\
5 & $3,500,000,000,000$ & $10 \%$ & $310,000,000,000$ & $1,550,000,000,000$ & $1,950,000,000,000$ \\
6 & $3,500,000,000,000$ & $10 \%$ & $310,000,000,000$ & $1,860,000,000,000$ & $1,640,000,000,000$ \\
7 & $3,500,000,000,000$ & $10 \%$ & $310,000,000,000$ & $2,170,000,000,000$ & $1,330,000,000,000$ \\
8 & $3,500,000,000,000$ & $10 \%$ & $310,000,000,000$ & $2,480,000,000,000$ & $1,020,000,000,000$ \\
9 & $3,500,000,000,000$ & $10 \%$ & $310,000,000,000$ & $2,790,000,000,000$ & $710,000,000,000$ \\
10 & $3,500,000,000,000$ & $10 \%$ & $310,000,000,000$ & $3,100,000,000,000$ & $400,000,000,000$ \\
\hline
\end{tabular}

Sumber : Pengolahan Data Microsoft Excell

Perhitungan cash in atau pendapatan distribusi crude oil dari selat Bangka Muntok ke Pertamina RU III Palembang untuk pertahunnya dengan pengaruh tingkat inflasi $=0.02$ persen pertahun.

Tabel 2. Nilai crude oil tahun 2017 (cash in)

\begin{tabular}{|ccccc|}
\hline No & $\begin{array}{c}\text { Crude Oil } \\
\text { (bl) }\end{array}$ & Harga USD & $\begin{array}{c}\text { Crude Oil } \\
\text { (liter) }\end{array}$ & Harga Rp \\
\hline 1 & $9,705,862 b 1$ & $\$ 496,843,076$ & $1,543,134,999$ & Rp.6,736,695,264,501 \\
\hline
\end{tabular}

Sumber :PT Pertamina RU III Plaju, 2017

Keterangan : Harga \&Kurs 2017

Harga crude oil tahun2017=\$51.19

Kurs Rp tahun tahun $2017=$ Rp. 13.559

$1 b l=158.99$ liter 159 liter

Kuantitas distribusi (bl) crude oil pertahun = $9,705,862$ bl/tahun, dengan harga perbarel $=$ $\$ 51.19 / \mathrm{bl}$ tahun 2017 , kurs rupiah $=\mathrm{Rp} 13,559$ tahun 2017 dengan tingkt inflasi 0.02/tahun.

Tahun $1=9,705,862$ bl x $\$ 51.19=\$ 496,843,076$

$=\$ 496,843,076 \times \operatorname{Rp} 13,559$

$=\operatorname{Rp~6,736,695,267,484~}$

Tahun $2=9,705,862$ bl x $\$ 51.19=\$ 496,843,076$ $=\$ 496,843,076 \times \operatorname{Rp~13,830}$

$=\operatorname{Rp} 6,871,429,172,834$

Tahun $3=9,705,862$ bl x $\$ 51.19=\$ 496,843,076$

$=\$ 496,843,076 \times \operatorname{Rp} 14,107$

$=\operatorname{Rp} 7,008,857,756,290$

dan seterusnya.

Tabel 3. Distribusi crude oil (cash in)

\begin{tabular}{|c|c|c|c|c|c|}
\hline Tahun & Distribusi & Kuantitas (bl) & Cash In $\$$ & Nilai Kurs Rp & Cash In Rp \\
\hline 1 & Crude oil & $9,705,862$ & $496,843,076$ & 13,559 & $6,736,695,267,484$ \\
\hline 2 & Crude oil & $9,705,862$ & $496,843,076$ & 13,830 & $6,871,429,172,834$ \\
\hline 3 & Crude oil & $9,705,862$ & $496,843,076$ & 14,107 & $7,008,857,756,290$ \\
\hline 4 & Crude oil & $9,705,862$ & $496,843,076$ & 14,389 & $7,149,034,911,416$ \\
\hline 5 & Crude oil & $9,705,862$ & $496,843,076$ & 14,677 & $7,292,015,609,644$ \\
\hline 6 & Crude oil & $9,705,862$ & $496,843,076$ & 14,970 & $7,437,855,921,837$ \\
\hline 7 & Crude oil & $9,705,862$ & $496,843,076$ & 15,270 & $7,586,613,040,274$ \\
\hline 8 & Crude oil & $9,705,862$ & $496,843,076$ & 15,575 & $7,738,345,301,080$ \\
\hline 9 & Crude oil & $9,705,862$ & $496,843,076$ & 15,887 & $7,893,112,207,101$ \\
\hline 10 & Crude oil & $9,705,862$ & $496,843,076$ & 16,204 & $8,050,974,451,243$ \\
\hline \multicolumn{5}{c}{ Nilai kurs rupiah dipengaruhi inflasi $(0.02)$} \\
\hline
\end{tabular}

Sumber data : Hasil Pengolahan Microsoft Excell

Perhitungan cash out atau pengeluaran PT Pertamina RU III dari proses distribusi crude oil dari selat Bangka Muntok ke Pertamina RU III Plaju Palembang setiap tahunnya dengan pengaruh tingkat inflasi $=0.02$ persen pertahun. 
Tabel 4. Losses crude oil (cash out)

\begin{tabular}{cccccc}
\hline Tahun & Losses & $\begin{array}{c}\text { Kuantit } \\
\text { as (bl) }\end{array}$ & $\begin{array}{c}\text { Cash } \\
\text { Out } \$\end{array}$ & $\begin{array}{c}\text { Nilai } \\
\text { Kurs } \\
\mathrm{Rp}\end{array}$ & $\begin{array}{c}\text { Cash out } \\
\text { Rp }\end{array}$ \\
\hline 1 & Crude oil & 428,386 & $21,929,079$ & 13,559 & $297,336,382,161$ \\
2 & Crude oil & 428,386 & $21,929,079$ & 13,830 & $303,283,109,804$ \\
3 & Crude oil & 428,386 & $21,929,079$ & 14,107 & $309,348,772,000$ \\
4 & Crude oil & 428,386 & $21,929,079$ & 14,389 & $315,535,747,440$ \\
5 & Crude oil & 428,386 & $21,929,079$ & 14,677 & $321,846,462,389$ \\
6 & Crude oil & 428,386 & $21,929,079$ & 14,970 & $328,283,391,637$ \\
7 & Crude oil & 428,386 & $21,929,079$ & 15,270 & $334,849,059,470$ \\
8 & Crude oil & 428,386 & $21,929,079$ & 15,575 & $341,546,040,659$ \\
9 & Crude oil & 428,386 & $21,929,079$ & 15,887 & $348,376,961,472$ \\
10 & Crude oil & 428,386 & $21,929,079$ & 16,204 & $355,344,500,702$ \\
\hline \multicolumn{6}{c}{ Nilai kurs rupiah dipengaruhi inflasi $(0.02)$} \\
\hline Sumber data : Hasil Pengolahan Microsoft Excell
\end{tabular}

Sumber data : Hasil Pengolahan Microsoft Excell

A. Biaya Operasional Proses Produksi Crude Oil

Tahun 1 , biaya proses produksi $=$

Rp2,594,678,106,994

Tahun 2, biaya proses produksi dipengaurhi inflasi $=0.02$, jadi

$=\mathrm{Rp} 2,594,678,106,994 \times(1+0.02)=$

Rp2,646,571,669,133 dan sampai tahun ke

10 tetap dipengaruhi inflasi $=0.02 /$ tahun .

B. Biaya Losses Crude Oil

Tahun 1, losses crude oil $=$ Rp297,336,382,161

Tahun 2, losses crude oil dipengaurhi inflasi $=0.02$, jadi

$=\mathrm{Rp} 297,336,382,161 \times(1+0.02)=$

Rp303,283,109,804 dan sampai tahun ke 10 tetap dipengaruhi inflasi $=0.02 /$ tahun.

C. Biaya Operasional STS

a. Biaya Sewa Tag Boat

Tahun 1, sewa tag boat $=3$ kapal per

tahun x Rp22,000,000,000

$=\mathrm{Rp} 66,000,000,000$

Tahun 2, sewa tag boat dipengaurhi

inflasi $=0.02$, jadi

$=\mathrm{Rp} 66,000,000,000 \times(1+0.02)=$

Rp67,320,000,000, dan sampai tahun ke

10 tetap dipengaruhi inflasi $=0.02 /$ tahun.

b. Biaya Bunker (MGO-1)

Tahun 1, biaya bunker $($ MGO-1) $=$

$114,480 \mathrm{jt}$ liter/tahun x 5,150/liter

$=\mathrm{Rp} 589,572,000$

Tahun 2, biaya bunker (MGO-1)

dipengaurhi inflasi $=0.02$, jadi

$=\operatorname{Rp} 589,572,000 \times(1+0.02)=$

IDR601,363,440 dan sampai tahun ke 10 tetap dipengaruhi inflasi $=0.02 /$ tahun.

c. Sewa Mother Ship (50 kapal/tahun)

Tahun 1, sewamother ship $=50$ kapal

pertahun x Rp19,000,000,000

$=\mathrm{Rp} 950,000,000,000$

Tahun 2, sewa mother ship dipengaurhi inflasi $=0.02$, jadi
$=\mathrm{Rp} 950,000,000,000 \times(1+0.02)=$

Rp969,000,000,000, dan sampai tahun ke 10 tetap dipengaruhi inflasi $=0.02 /$ tahun.

d. Sewa Shuttle Ship (139 kapal/tahun)

Tahun 1, shuttle ship = 139 kapal/tahun $\mathrm{x}$ Rp6,800,000,000

$=$ Rp945,200,000,000

Tahun 2, shuttle ship dipengaurhi inflasi

$=0.02$, jadi

$=\operatorname{Rp} 945,200,000,000 \times(1+0.02)=$

Rp964,104,000,000

Dan sampai tahun ke 10 tetap dipengaruhi inflasi $=0.02 /$ tahun .

e. Perizinan Syahbandar ( $52 \mathrm{minggu} / \mathrm{tahun}$ ) Tahun 1 , syahbandar $=52 \mathrm{minggu} /$ tahun x Rp177,000,000

$=\mathrm{Rp} 9,204,000,000$

Tahun 2, perizinan syahbandar dipengaurhi inflasi $=0.02$, jadi $=\mathrm{Rp} 9,204,000,000 \times(1+0.02)=$ Rp9,388,080,000

Dan sampai tahun ke 10 tetap dipengaruhi inflasi $=0.02 /$ tahun .

f. Marine Guard (365 hari/tahun)

Tahun 1, marine guard $=365$ hari/tahun x Rp70,000,000

$=\mathrm{Rp} 25,550,000,000$

Tahun 2, marine guard dipengaurhi

inflasi $=0.02$, jadi

$=\operatorname{Rp} 25,550,000,000 \times(1+0.02)=$

Rp26,061,000,000

Dan sampai tahun ke 10 tetap dipengaruhi inflasi $=0.02 /$ tahun .

g. Maintenance Rutin (10 item/tahun)

Tahun 1, maintenance rutin $=10$

item/tahun x Rp3,000,000,000

$=\mathrm{Rp} 30,000,000,000$

Tahun 2, maintenance rutin dipengaurhi inflasi $=0.02$, jadi

$=\operatorname{Rp} 30,000,000,000 \times(1+0.02)=$

Rp30,600,000,000

Dan sampai tahun ke 10 tetap

dipengaruhi inflasi $=0.02 /$ tahun .

h. Biaya Listrik Kapal

Tahun 1 , listrik kapal $=$

Rp674,000,000,000

Tahun 2, listrik kapal dipengaurhi inflasi

$=0.02$, jadi

$=\operatorname{Rp} 674,000,000,000 \times(1+0.02)=$

Rp687,480,000,000

Dan sampai tahun ke 10 tetap

dipengaruhi inflasi $=0.02 /$ tahun

i. Biaya Air Bersih Kapal

Tahun 1, air bersih kapal =

Rp1,200,000,000

Tahun 2, air bersih kapal dipengaurhi

inflasi $=0.02$, jadi

$=\mathrm{Rp} 1,200,000,000 \times(1+0.02)=$

Rp1,224,000,000

Dan sampai tahun ke 10 tetap

dipengaruhi inflasi $=0.02 /$ tahun 
D. Biaya Tenaga Kerja Langsung

a. Karyawan Operasional STS

Tahun 1, karyawan STS $=20$ karyawan $\mathrm{x}$

Rp15,000,000 x 12 bulan

$=$ Rp3,600,000,000

Tahun 2, karyawan STS dipengaurhi

inflasi $=0.02$, jadi

$=\mathrm{Rp} 3,600,000,000 \times(1+0.02)=$

Rp3,672,000,000

Dan sampai tahun ke 10 tetap dipengaruhi inflasi $=0.02 /$ tahun

b. Crew Kapal

Tahun 1, crew kapal $=80$ karyawan $\mathrm{x}$

Rp6,500,000 x 12 bulan

$=$ Rp6,240,000,000

Tahun 2, crew kapal dipengaurhi inflasi $=$ 0.02 , jadi

$=\mathrm{Rp} 6,240,000,000 \times(1+0.02)=$

Rp6,364,000,000

Dan sampai tahun ke 10 tetap dipengaruhi inflasi $=0.02 /$ tahun

c. Karyawan Maintenance

Tahun 1 , maintenance $=30$ karyawan $\mathrm{x}$

Rp6,500,000 x 12 bulan

$=\mathrm{Rp} 2,340,000,000$

Tahun 2, maintenance dipengaurhi inflasi $=0.02$, jadi

$=\mathrm{Rp} 2,340,000,000 \times(1+0.02)=$

Rp2,386,800,000

Dan sampai tahun ke 10 tetap dipengaruhi inflasi $=0.02 /$ tahun .

E. Biaya Lainnya

a. Administrasi Lain

Tahun 1, administrasi lain $=$

Rp1,347,339,053

Tahun 2, administrasi lain dipengaurhi inflasi $=0.02$, jadi

$=\mathrm{Rp} 1,347,339,053 \times(1+0.02)=$

Rp1,374,285,835

Dan sampai tahun ke 10 tetap dipengaruhi inflasi $=0.02 /$ tahun .

b. Biaya Konsumsi Pekerja

Tahun 1, konsumsi = Rp67,366,952,675

Tahun 2, konsumsi dipengaurhi inflasi $=$ 0.02 , jadi

$=\operatorname{Rp} 67,366,952,675 \times(1+0.02)=$

Rp68,714,291,728

Dan sampai tahun ke 10 tetap dipengaruhi inflasi $=0.02 /$ tahun .

c. Biaya Perlengkapan Pekerja

Tahun 1, perlengkapan $=$

Rp26,946,781,070

Tahun 2, perlengkapan dipengaurhi inflasi $=0.02$, jadi

$=\mathrm{Rp} 26,946,781,070 \times(1+0.02)=$

Rp27,485,716,691

Dan sampai tahun ke 10 tetap dipengaruhi inflasi $=0.02 /$ tahun

d. Biaya Lainnya
Tahun 1, lainnya $=$ Rp6,736,695,267

Tahun 2,lainnya dipengaurhi inflasi $=0.02$, jadi

$=\mathrm{Rp} 6,736,695,267 \times(1+0.02)=$

Rp6,871,429,173

Dan sampai tahun ke 10 tetap dipengaruhi inflasi $=0.02 /$ tahun

e. Biaya Asuransi Karyawan STS

Tahun 1, lainnya $=\mathrm{Rp} 2,600,000,000$

Tahun 2,lainnya dipengaurhi inflasi $=0.02$, jadi

$=\mathrm{Rp} 2,600,000,000 \times(1+0.02)=$

Rp2,652,000,000

Dan sampai tahun ke 10 tetap dipengaruhi inflasi $=0.02 /$ tahun .

Perhitungan laba rugi, yang merupakan pengurangan dari cash in dan cash out PT Pertamina RU III dari proses distribusi crude oil dari selat Bangka Muntok ke Pertamina RU III Palembang dengan pengaruh tingkat inflasi

$=0.02$ persen pertahun.sehingga nantinya akan memciptakan arus kas bersih sebagai acuan perhitungan nilai NPV dan IRR.

\section{A. Total Cash Out}

Variabel cost ${ }^{+}$fixed cost (biaya operasional STS dan biaya tenaga kerja langsung + biaya lainnya, perhitungan dilakukan sampai tahun ke-10.

B. Laba Kotor

Cash in (pendapatan) dari distribusi crude oil - total cash out (pengeluaran) dari proses operasional STS dan losses cost distribusi crude oil.

Tahun $1=6,736,695,267,484-$

$5,710,935,829,220$

$=\operatorname{Rp} 811,031,606,875$

Perhitungan dilakukan sampai dengan tahun ke-10.

C. Laba Sebelum Pajak

Laba kotor - nilai depresiasi.Perhitungan dilakukan sampai dengan tahun ke-10.

D. Pajak 30\%/tahun Laba sebelum pajak x 30 \%.Perhitungan dilakukan sampai dengan tahun ke-10.

E. Laba Bersih

Laba sebelum pajak - pajak $30 \% /$ tahun.Perhitungan dilakukan sampai dengan tahun ke-10.

F. Arus Kas Bersih Laba bersih + nilai depresiasi,.Perhitungan dilakukan sampai dengan tahun ke-10.

Perhitungan NPV dan IRR dengan acuan nilai arus kas bersih, baik investasi secara membeli ataupun investasi secara rental, dengan ketentuan faktor diskonto $=12 \%$ dan $23 \%$, dan nilai MARR $=15 \%$. 
Tabel 5. Perhitungan NPV investasi sistem baru distribusi crude oil dengan acuan arus kas bersih (discount rate 0.12 )

\begin{tabular}{|c|c|c|c|}
\hline $\begin{array}{l}\text { Jumlah } \\
\text { Periode }\end{array}$ & 10 & \multirow{2}{*}{$\begin{array}{c}\text { Discount } \\
\text { Rate }(0.12)\end{array}$} & \multirow{4}{*}{ Present Value } \\
\hline $\begin{array}{c}\text { Faktor } \\
\text { Diskonto }\end{array}$ & 0.12 & & \\
\hline $\begin{array}{c}\text { Investasi } \\
\text { Awal }\end{array}$ & $3,500,000,000,000$ & \multirow[t]{2}{*}{ Table NPV } & \\
\hline Periode & Aliran Kas Masuk & & \\
\hline 0 & $(3,500,000,000,000)$ & & $(3,500,000,000,000)$ \\
\hline 1 & $811,031,606,785$ & 0.8929 & $724,170,121,698$ \\
\hline 2 & $825,392,238,920$ & 0.7972 & $658,002,692,867$ \\
\hline 3 & $902,720,889,710$ & 0.7118 & $642,556,729,296$ \\
\hline 4 & $919,035,427,504$ & 0.6355 & $584,047,014,179$ \\
\hline 5 & $935,676,256,055$ & 0.5674 & $530,902,707,685$ \\
\hline 6 & $952,649,901,176$ & 0.5066 & $482,612,439,936$ \\
\hline 7 & $969,963,019,199$ & 0.4523 & $438,714,273,584$ \\
\hline 8 & $987,622,399,583$ & 0.4039 & $398,900,687,192$ \\
\hline 9 & $1,005,634,967,575$ & 0.3606 & $362,631,969,307$ \\
\hline \multirow[t]{3}{*}{10} & $1,024,007,786,926$ & 0.3220 & $329,730,507,390$ \\
\hline & & NPV & $5,152,269,143,134$ \\
\hline & & NPV & $1,652,269,143,134$ \\
\hline
\end{tabular}

Sumber data : Hasil Pengolahan Microsoft Excell

Tabel 6. Perhitungan NPV investasi sistem baru distribusi crude oil dengan acuan arus kas bersih (discount rate 0.23 )

\begin{tabular}{cc|c|c}
\hline $\begin{array}{c}\text { Faktor } \\
\text { Diskonto }\end{array}$ & $\mathbf{1 0}$ & $\begin{array}{c}\text { Discount Rate } \\
(\mathbf{0 . 2 3})\end{array}$ & \multirow{2}{*}{ Present Value } \\
\cline { 1 - 2 } $\begin{array}{c}\text { Investasi } \\
\text { Awal }\end{array}$ & $\mathbf{3 , 5 0 0 , 0 0 0 , 0 0 0 , 0 0 0}$ & \multirow{2}{*}{ Table NPV } & \\
\cline { 1 - 2 } Periode & Aliran Kas Masuk & & \\
\cline { 1 - 3 } 0 & $(3,500,000,000,000)$ & & $(3,500,000,000,000)$ \\
1 & $811,031,606,785$ & 0.8130 & $659,375,290,069$ \\
2 & $825,392,238,920$ & 0.6610 & $545,569,594,104$ \\
3 & $902,720,889,710$ & 0.5374 & $485,107,688,895$ \\
\hline
\end{tabular}

Sumber data : Hasil Pengolahan Microsoft Excell

Tabel 7. Perhitungan NPV investasi sistem baru distribusi crude oil dengan acuan arus kas bersih (discount rate $0.23)$

\begin{tabular}{|c|c|c|c|}
\hline $\begin{array}{l}\text { JUMLAH } \\
\text { PERIODE }\end{array}$ & 10 & \multirow{2}{*}{$\begin{array}{c}\text { DISCOUNT RATE } \\
\quad(0.23)\end{array}$} & \multirow{4}{*}{$\begin{array}{l}\text { PRESENT } \\
\text { VALUE }\end{array}$} \\
\hline $\begin{array}{c}\text { FAKTOR } \\
\text { DISKONTO }\end{array}$ & 0.23 & & \\
\hline $\begin{array}{c}\text { INVESTASI } \\
\text { AWAL } \\
\end{array}$ & $3,500,000,000,000$ & \multirow{2}{*}{ TABLE NPV } & \\
\hline PERIODE & $\begin{array}{l}\text { ALIRAN KAS } \\
\text { MASUK } \\
\end{array}$ & & \\
\hline 4 & $919,035,427,504$ & 0.4369 & $401,524,275,724$ \\
\hline 5 & $935,676,256,055$ & 0.3552 & $332,353,343,110$ \\
\hline 6 & $952,649,901,176$ & 0.2888 & $275,107,644,295$ \\
\hline 7 & $969,963,019,199$ & 0.2348 & $227,729,554,526$ \\
\hline 8 & $987,622,399,583$ & 0.1909 & $188,516,791,588$ \\
\hline 9 & $1,005,634,967,575$ & 0.1552 & $156,060,991,978$ \\
\hline \multirow[t]{2}{*}{10} & $1,024,007,786,926$ & 0.1262 & $129,196,915,361$ \\
\hline & & $\begin{array}{l}\text { NPV } \\
\text { NPV }\end{array}$ & $\begin{array}{c}3,400,542,089,650 \\
(\mathbf{9 9 , 4 5 7 , 9 1 0 , 3 5 0 )}\end{array}$ \\
\hline
\end{tabular}

Sumber data : Hasil Pengolahan Microsoft Excell

Tabel 8. Perhitungan IRR investasi sistem baru distribusi crude oil dengan acuan arus kas bersih

\begin{tabular}{ccc}
\hline \multicolumn{3}{c}{ Perhitungan interpolasi : Internal Rate of Return } \\
\hline \multirow{2}{*}{ Selisih Bunga } & Selisih PV & $\begin{array}{c}\text { Selisih PV dengan } \\
\text { Investasi Awal }\end{array}$ \\
\hline $23 \%$ & $(99,457,910,350)$ & $3,500,000,000,000$ \\
$12 \%$ & $1,652,269,143,134$ & $5,152,269,143,134$ \\
$11 \%$ & $1,751,727,053,484$ & $1,652,269,143,134$ \\
\hline IRR $=$ & $12 \%+(\mathrm{Rp} .1,652,269,143,134 / \mathrm{Rp} .1,751,727,053,484) \times 11 \%$ \\
\hline $\mathrm{IRR}=$ & & $22.38 \%$
\end{tabular}

Sumber data : Hasil Pengolahan Microsoft Excell
Tabel 9. Perhitungan payback period investasi sistem baru distribusi crudeoil dengan acuan arus kas bersih

\begin{tabular}{c|c|c}
\hline \multicolumn{2}{c}{ PERHITUNGAN PAY BACK PERIOD } \\
\cline { 1 - 2 } $\begin{array}{c}\text { JUMLAH } \\
\text { PERIODE }\end{array}$ & $\mathbf{1 0}$ & \multirow{2}{*}{ PAYBACK PERIOD } \\
\cline { 1 - 2 } INVESTASI & $\mathbf{3 , 5 0 0 , 0 0 0 , 0 0 0 , 0 0 0}$ & \\
\hline AWAL & ALIRAN KAS MASUK & \\
\hline PERIODE & $(3,500,000,000,000)$ & $(3,500,000,000,000)$ \\
$\mathbf{0}$ & $811,031,606,785$ & $(2,688,968,393,215)$ \\
$\mathbf{1}$ & $825,392,238,920$ & $(1,863,576,154,295)$ \\
$\mathbf{2}$ & $902,720,889,710$ & $(960,855,264,585)$ \\
\hline
\end{tabular}

Sumber data : Hasil Pengolahan Microsoft Excell

Tabel (Lanjutan ) 10. Perhitungan payback period investasi sistem baru distribusi crudeoil dengan acuan arus kas bersih

\begin{tabular}{c|c|c}
\hline \multicolumn{3}{|c}{ PERHITUNGAN PAY BACK PERIOD } \\
\cline { 1 - 2 } $\begin{array}{c}\text { JUMLAH } \\
\text { PERIODE }\end{array}$ & $\mathbf{1 0}$ & \multirow{2}{*}{ PAYBACK PERIOD } \\
\cline { 1 - 2 } $\begin{array}{c}\text { INVESTASI } \\
\text { AWAL }\end{array}$ & $\mathbf{3 , 5 0 0 , 0 0 0 , 0 0 0 , 0 0 0}$ & \\
\hline PERIODE & ALIRAN KAS MASUK & $(41,819,837,080)$ \\
\cline { 1 - 1 } & $919,035,427,504$ & $893,856,418,974$ \\
$\mathbf{5}$ & $935,676,256,055$ & $1,846,506,320,150$ \\
$\mathbf{6}$ & $952,649,901,176$ & $2,816,469,339,349$ \\
$\mathbf{7}$ & $969,963,019,199$ & $3,804,091,738,932$ \\
$\mathbf{8}$ & $987,622,399,583$ & $4,809,726,706,507$ \\
$\mathbf{9}$ & $1,005,634,967,575$ & $5,833,734,493,433$ \\
$\mathbf{1 0}$ & $1,024,007,786,926$ & \\
\hline
\end{tabular}

Sumber data : Hasil Pengolahan Microsoft Excell

\section{KESIMPULAN}

Dari penelitian yang telah dilakukan didapatkan kesimpulan bahwa arus kas bersih yang tercipta setiap tahunnya memiliki nilai yang positif dengan nominal awal rencana investasi sistem baru yaitu sebesar Rp 3,500,000,000,000. Dari perhitungan didapatkan nilai IRR $=22.38 \%>$ MARR $=15 \%$, yang artinya nilai alternative investasi sistem baru (instalasi pipa dan tanki timbun) distribusi crude oil layak (menguntungkan) untuk dijalankan. Didukung dengan payback period yang baik, yaitu selama 5 tahun. Serta alternative investasi sitem baru (instalasi pipa dan tanki timbun)meminimalkan nilai losses distribusi crude oil, dimana nilai losses alternative sistem baru = $42,500 \mathrm{bl}<$ dari nilai losses sistem lama $=428,386$ bl.

Berdasarkan hasil kesimpulan, rencana investasi sistem baru baik dilakukan,karena memberikan profit yang baik bagi perusahaan PT Pertamina RU III Palembang. Didukung dengan dokumentasi data nilai losses dari sistem baru yang kecil dengan payback period nilai investasi yang baik.Dan untuk penelitian selanjuntnya penelitian ini dapat digunakan sebagai bahan pembanding dan acuan untuk penelitian, guna membantu menyempurnakan hasi penelitian. 


\section{DAFTAR PUSTAKA}

[1] Bodie, Z, Kane.A; Marcus, A.J. 1995. Essential Og Investment, 2nd edition, Washington: Richard D. Irwin Inc

[2] Francis, J.C. 1991.Investment : Analysis and Management, 5th. Singapore: McGrawhill INC

[3] Raharjaputra, Hendra S, 2009, " Buku Panduan Praktis Manajemen Keuangan dan Akutansi untuk Eksekutif Perusahaan", Jakarta, Salemba Empat.

[4] Ristono, Agus, Puryani, 2011, "Ekonomi Teknik" Yogyakarta, Edisi 1, Graha Ilmu.

[5] Siregar, Baldric, Dkk, 2014, "Akutansi Manajemen", Jakarta Selatan, Salemba Empat. , Jurnal Akutansi

[6] Suratman. 2001. Studi Kelayakan Proyek: Teknik dan Prosedur PenyusunanLaporan. Yogyakarta : J \& J Learning

[7] Sinaga, Dadjim. 2009. Studi Kelayakan Bisnis Dalam Ekonomi Global: Teori dan Aplikasinya dalam Evaluasi Proyek. Jakarta : Mitra Wacana Media

[8] Sinaga, Dadjim, \& Saragih, Herlina J. R. 2013.Studi Kelayakan Investasi Pada Proyek Dan Bisnis Dalam Perspektif Iklim Investasi Perekonomian Global: Teori dan Aplikasinya dalam Menilai Investasi Modal dalam Proyek dan Bisnis). Jakarta : Mitra Wacana MediaJilid 5, No. 4, (http://www.malang.ac.id, diakses 20 Januari 2000).

[9] Dwipriyoko, E., Bon, A. T. B., \& Sukono, F. (2019), Enterprise Architecture Planning as New Generation Cooperatives Research Methods, Journal of Physics: Conference Series (Vol. 1179, No. 1, p. 012094), IOP Publishing. 